\title{
A new model for the development of mobile e-commerce-The WeChat Reservation mode
}

\author{
Chunlei Han ${ }^{1, a}$, Shucui Shi ${ }^{2, b}$ and Fangfang $\mathrm{Liu}^{3, \mathrm{c}}$ \\ ${ }^{1}$ Qingdao Huanghai University, Qingdao 266427, China; \\ ${ }^{2}$ Qingdao Huanghai University, Qingdao 266427, China; \\ ${ }^{3}$ Qingdao Huanghai University, Qingdao 266427, China; \\ achentongab@163.com, bchentongab@163.com, chentongab@163.com
}

Keywords: The wechat, Reservation system,mobile e-commerce,online and offline O2O.

\begin{abstract}
The wechat reservation system is a self-ordering system by using wechat. With the popularity of the wechat and mobile e-commerce, the advantage of the wechat reservation system is displayed completely. The wechat, combining the offline services with internet system, attracts customers online and assures offline service of customer to clinch a deal. The menu of restaurant is shown on the the wechat in public, which is convenient for the customer to know your restaurant features, browse menu online, order a delivery meal by a key of a telephone or place delivery orders online by the wechat. Attractive offers or promotions can be sent periodically on micro letter, and also exclusive privilege can be provided to members, attracting customers to visit many times.
\end{abstract}

\section{Introduction}

The wechat reservation system makes users to establish contact with the business, you can enjoy a full-service.Through the wechat reservation system self-service,customers can order dishes. Businessmen can view order information and delivery on time, and establish an interactive relationship with customers after the distribution is completed. Businessmen expand business through interaction; this model completely changed the traditional ordering patterns while saving money on labor expenses, operating expenses.

\section{Project introduction}

In this paper,the background is the a wechat reservation system which is students' innovation program.He has his own office at the business street opposite the school. Businessmen use the wechat public platform to manage goods orders, cooperate with the surrounding restaurants, beverage shops and supermarkets, and then put their product on the platform. The main function of micro channel ordering system:

\subsection{Reservation function.}

The wechat platform establish partnerships with businessmen and put their menu on the platform while promoting its own wechat public platform to establish a large user base.Consumers can log online platform,submit orders after entering the correct information. The staff of platform log system to view orders. The staff of platform contact the businessmen to make the dishes, and arrange delivery.

\subsection{Express function.}

Businessmen can interact with customers through the wechat platform, but the courier can achieve direct dialogue with customers.Courier delivery on time while providing express service to the customer.Through reasonable staff scheduling, the ordering platform take full advantage of existing courier, reducing labor costs, creating two-way profit, creating new revenue streams for the sustainable development of wechat reservation patterns. 


\subsection{Information and advertising function.}

After a user adds the wechat platform, he has become a potential customer, businessmen can take promotional activities for customers and gradually improve the quality of services. With the continuous expansion and constantly building brand influence,in order to establish good customer relations, the wechat platform provide customers with relevant information consulting services, such as travel information, carpool information, part-time information. With the increasing customer base size, you can use the system to advertise services and increase profits.

\section{The advantages of the wechat reservation mode}

The wechat reservation mode is a typical application of mobile age of electronic commerce $\mathrm{O} 2 \mathrm{O}$ mode, with the application and development of mobile internet technology, the wechat reservation mode pattern has been accepted overwhelmingly among majority of users. Advantages of the wechat reservation mode are as follows:

\subsection{Improve ordering speed and cost savings.}

Consumers use mobile micro-channel reservation system, you only need to scan QR code number of public business, all the business information will be stored in the wechat.Businessmen use the platform to advertising information, both environment friendly and low cost, and also make businessmen's precise target. Food distribution mainly make for student groups, students live concentrated, which makes delivery more efficient, delivering once can meet the multiple needs of students.Consumers only need to enter a phone, address and other information once and do not need to fill in again, just one minute to complete the reservation.

\subsection{Promotion targeted and high efficiency.}

When businessmen use the wechat for marketing, businessmen can set up different categories based on consumer preferences, geographical, adding time and other information, so that businessmen can easily understand and grasp the user's preferences and achieve precise message push.Businessmen should pay attention to value of the sent a message, for consumers will put this valuable information in the circle of friends to share, thus increasing business visibility, improving the promotion of efficiency.

\subsection{Enhanced interactivity between businessmen and consumers, helping to train customer} loyalty.

Consumers will share valuable information and a good consumer experience through wechat, numerous wechat friends will see these share,these good reviews are affecting other consumer behavior.Business men's products and services obtain the recognition of consumers, and this recognition spread through wechat, which is the best way to promote low-cost for businessmen, which increases the visibility of the intangible business products and services. Businessmen create a good corporate image through word of mouth.In order to narrow the distance with customers, reduce the cost of communication between the customer and the merchant, the merchant can set artificial customer service, which can achieve real-time communication between people and avoid misunderstandings caused by miscommunication.

\subsection{Marketing online and offline at the same time to achieve a new situation of consumption.}

Businessmen are fully aware of the important role of wechat marketing,businessmen use QR code to establish a huge consumer groups.QR codes are widely appear on restaurant menus, on the business desktop. Consumers can easily focus on business wechat platform via QR codes. Businessmen provide discounts and promotions on wechat platform to encourage consumer consume again.At the same time, businessmen enhanced offline consumer experience, improve service quality, create a good environment for consumption, increase consumers' favorable impression of businessmen. This approach not only increase the number of consumers for the wechat platform, but also accumulate a large number of actual consumer groups, which is essential to carry out the latter part of the wechat marketing. 


\section{The disadvantages of the wechat reservation mode}

\subsection{Malicious consumer orders.}

Consumer order is the start of all business activities in wechat reservation mode, the starting point will affect the business inventories of goods, the supplier inquiry, coordination of supplier delivery, logistics and distribution arrangements and other aspects.If the consumer appears malicious behavior orders, which will directly lead to businessmen's waste of manpower and resources, and even cause businessmen's significant economic losses.

\subsection{Prone to the problem of information overload and the loss of customers.}

While the wechat can transmit a lot of information only charging a small traffic costs, this does not mean you can send all kinds of junk information to consumers. Wechat marketing is based on a strong network of relationships, a consumer and a large number of user groups are often linked, if the user disregards the feelings of others, and is forced to push a variety of unattractive advertising information, which makes poor marketing results, users will even be lead to resentment and lose interest in the business.

\subsection{Businessmen and consumers communicate ineffectively.}

Most of the employees are engaged in activities offline, there is little time to focus on the views of consumers online, or do not respond to the views of consumers for the first time, which makes normal exchange impossible between consumers and businessmen.Although businessmen can set up a custom reply on the wechat platform, but when consumers really need a complaint, the reply will become a decoration, so most wechat platform did not play the role of customer service.

\subsection{New marketing model emerging in mobile e-commerce era,facing enormous competitive} pressure.

Currently the wechat can be used with mobile internet applications which extends the profit channel of the wechat platform, increasing source of profit.With the continuous development of mobile internet technology, the threshold of mobile e-commerce platform reduced, while specialized marketing methods continue to emerge, competitive pressure is huge.If you do not own the brand, consumers can choose other professional platform for the purchase of products and services.

\section{Significance of the wechat reservation mode}

\subsection{This mode is Practice in university students provided the opportunity.}

As enterprises' urgent need for skilled personnel, the training program of the students' practical ability is also on the agenda, but now schools are generally lack of the resources and capacity-building methods in practice, the wechat provides a golden opportunity for universities.It is easy to build mobile e-commerce platform through the wechat, the platform allows students to participate in internships practice so that they are familiar with new media marketing companies ways, operational processes. It improveS students' innovation ability, and ultimately enableS students to truly meet the businessIt needs.

\subsection{Platform provideS new employment and business opportunities for college students.}

2015,the State Council promulgated the "vigorously promote the public on a number of policy measures to entrepreneurship highly innovative views" entrepreneurial innovation issue has become a new hot economic spot, entrepreneurship and innovation has become a national strategy.The emergence of wechat provides a good start in the form of low-cost.in school, many students are attempting to start a business by wechat. Good openness and freedom are characteristics of the wechat, which allows each participant to get a lot of information, And when you want to pass information to the audience, it can make your message received by a lot of people, also form a discussion group, where everyone constantly in discussion groups to share experiences. Students are generally lack the resources needed in the early days of entrepreneurship, which reduces the likelihood of entrepreneurial success.

The wechat provides a vivid form for college students to start entrepreneurship, the wechat can enable businessmen to communicate with customers through maps, text, sound, like a form, which is 
more intuitive display of products and services to customers.Businessmen can easily build product brands through the wechat, raising the possibility of entrepreneurial success.At the same time, colleges and universities also encourage students of innovation and entrepreneurshipto explore new models of innovation and entrepreneurship for students to provide the necessary support.Universities can establish cooperation with enterprises, allow enterprises to provide goods, guide college students to establish public internet.Then teachers guide students to develop entrepreneurial project team, establish a sound management system, establish a good marketing and sales process.

\subsection{This new model of mobile e-commerce has had an impact on the food industry, force them to make the transformation.}

Food industry is one of the most traditional industries in China, and is the most active areas of life. It is also a profound influence in the field in the Internet age. With increasing competition, the wechat has become an important way of promotion and marketing of products for most food and beverage companies.But how to make good use of micro-letters, how to make the brand to get the value in the number of fans, influence, marketing and other aspects, this is the challenge facing the food and beverage industry.

Dining $\mathrm{O} 2 \mathrm{O}$ is currently the fastest growing industry in the wechat platform, businessmen can accumulate a lot of word of mouth through every activity, while businessmen adjust marketing strategies based on consumer feedback, and tap the potential customer value. With the development of the internet, enterprises will be able to give consumers more consumer experience, more value-added services, more interactive communication on the platform, micro-channel platform in the future is not only able to meet consumer demand, it is also a terminal experience dissemination of media.

\subsection{Through wechat platform, enterprises develop online and offline marketing activities.}

A lot of information exists on the internet, it is very difficult to screen valuable information, the promotion of enterprise information is covered by vast amounts of useless information, so companies can conduct offline marketing activities,online and offline marketing activities are carried out simultaneously to enhance the company marketing effectiveness. When holding a new conference or holiday promotions, companies can take advantage of wechat text, voice, video and other means to instantly broadcast live on marketing activities, this will be the perfect picture of the activities presented, at the same time publicity, magnified the effect of publicity with traditional media.

Enterprises and users can communicate in real-time online through wechat, access to market information and analyzing marketing information, then make marketing planning for the customer situation.It not only can save resources, reduce marketing costs, but also meet consumer demand. Enterprises can set up automatic reply on wechat platform,response to user ontime and enhance the efficiency of communication with the user. In order to enhance communication with customers authenticity, enterprise send someone to reply to the difficult question. This will not only establish a good brand image, but also to narrow the distance between the user and the enterprise, improve management efficiency and customer satisfaction.

\section{Summary}

With the advent of $4 \mathrm{G}$ era, the speed of wireless networks continues to increase, rates continue to decline, mobile phones become the carrier for payment and consumer spending. The WeChat Reservation mode belongs to an emerging $\mathrm{O} 2 \mathrm{O}$ mobile e-commerce marketing model, consumers can order online, combine with physical stores and logistics, so that consumers feel fastness and convenience and high product quality of Internet age.

\section{References}

[1]. Yan Wang. E-commerce marketing analysis of the wechat. Market Modernization. Vol. 36 (2014) No. 13, p. 75-76.

[2]. Peipei Zuo.The discussion of wechat marketing Problems.China Business \& Trade. Vol. 36 (2013) No. 36, p. 32-33. 
[3]. Taidou Meng. Wechat marketing advantage in the $4 \mathrm{G}$ environment. Modern Business. Vol. 36 (2014) No. 6, p. 59-60.

[4]. Hong Zhang, YueWang. The discussion of College Students' entrepreneurship through wechat. China Newspaper Industry. Vol. 24 (2014) No. 14, p. 95-96.

[5]. Yanhong Zhang. The application of wechat in the enterprise network Marketing. China Business \& Trade. Vol. 36 (2014) No. 30, p. 85-86. 